\title{
Blood Loss in Surgery for Aggressive Vertebral Haemangioma with and without Embolisation
}

\author{
Yohan Robinson ${ }^{1}$, Reda Sheta ${ }^{2}$, Konstantin Salci ${ }^{3}$, Johan Willander ${ }^{4}$ \\ ${ }^{1}$ Department of Surgical Sciences, Uppsala University Hospital, Uppsala, Sweden \\ ${ }^{2}$ Department of Orthopaedic Surgery, Al Ahrar Specialised Hospital Zagazig, Zagazig, Egypt \\ ${ }^{3}$ Department of Neurosurgery, Uppsala University Hospital, Uppsala, Sweden \\ ${ }^{4}$ Department of Psychology, University of Gävle, Gävle, Sweden
}

Despite their benign nature some symptomatic aggressive vertebral haemangiomas (AVH) require surgery to decompress spinal cord and/or stabilise pathological fractures. Preoperative embolisation may reduce the considerable blood loss during surgical decompression. This systematic review investigated whether preoperative embolisation reduced surgical blood loss during treatment of symptomatic AVH. PubMed Medline, Web of Science, and Ovid Medline were searched for case reports and clinical studies on surgical AVH treatment. Included were cases from all publications on surgical treatment of AVH where the amount of surgical blood loss and the use of preoperative embolisation were documented. 51 cases with surgically treated AVH were retrieved from the included studies. Blood loss in the embolised treatment group $(980 \pm 683 \mathrm{~mL})$ was lower than the non-embolised control group $(1,629 \pm 946 \mathrm{~mL})$. This systematic review found that embolisation prior to AVH resection reduced surgical blood loss (level of evidence, very low) and can be recommended (strong recommendation).

Keywords: Spinal cord compression; Hemangioma; Therapeutic embolisation; Surgical blood loss

\section{Introduction}

Aggressive vertebral haemangiomas (AVH) are benign vascular tumours, which breach the posterior cortical wall of the affected vertebra, may affect anterior column stability, and compress the spinal cord epidurally [1]. Due to the benign nature of the tumour, metastatic spreading does not occur, but impaired vertebral stability or myelopathy may require surgical treatment for stabilisation and decompression [2]. A representative case is presented in Fig. 1.

Depending on the affected vertebral level and the anterior and posterior extent of the lesion, there are combined surgical accesses to decompress and stabilise AVH. Due to high vascularisation of haemangiomas, copious bleeding may complicate surgery, and can even be life-threatening [1].

Embolisation of spinal tumours via flouroscopicallycontrolled endovascular intervention aims at choking off the blood flow in the tumour by blocking the feeding arteries, and thus reducing surgical blood loss. Many substances can be used for embolisation depending of the size of the vessel and the desired length of occlusion [3]. Liquid embolic agents (i.e., Onyx) [4], sclerosing agents (i.e., ethanol) [5], particulate embolic agents (i.e., polyvinyl ethanol) [6], and mechanical occlusion devices (i.e., coils) are commonly used as embolising agents.

Yet, many spinal interventionalists fear the possibility

Received Nov 13, 2014; Accepted Nov 25, 2014

Corresponding author: Yohan Robinson

Department of Surgical Sciences, Uppsala University Hospital, 75185 Uppsala, Sweden

Tel: +46-18-6110000, Fax: +46-18-509427, E-mail: yohan.robinson@surgsci.uu.se 
of ischaemic spinal cord injury as a complication of the embolisation procedure due to accidental occlusion of unrecognised radiculomedullary arteries. Surgeons might therefore avoid performing embolisation and rather treat bleeding surgically. Possible complications of spinal tu- mour embolisation are (1) emboli washout with vascular occlusion (i.e., spinal cord ischaemia, stroke, myocardial infarction, peripheral arterial occlusion) [7], (2) bleeding due to early revascularisation caused by rapid enzymatic degradation of the embolisation agents (i.e., gelfoam) [8],
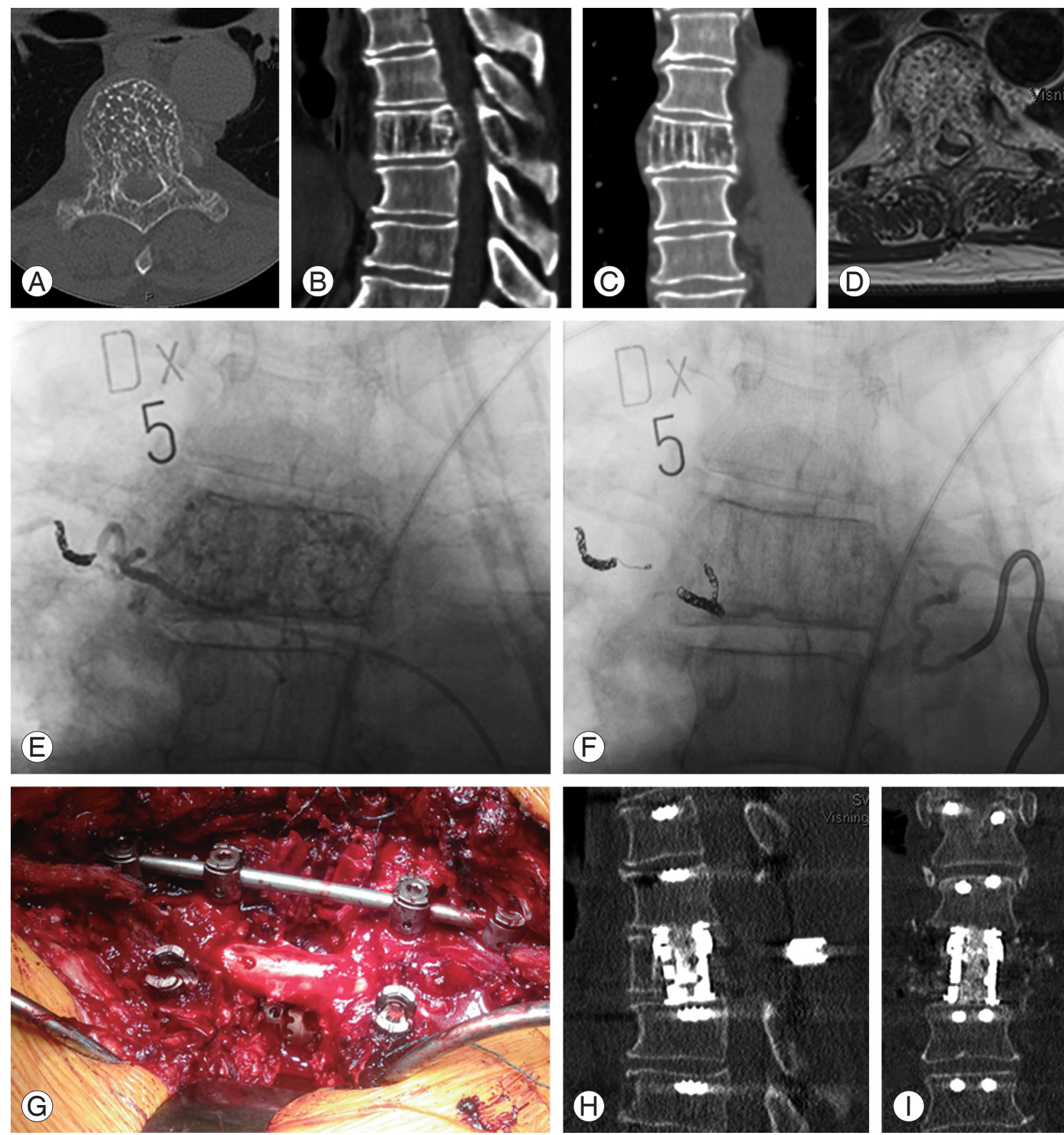

Fig. 1. Representative case of a 64-year-old man with progressive myelopathy below T6 (ASIA C). (A-C) Computed tomography (CT) scans revealed vertical striations on the T6 vertebral body, highly suggestive of haemangioma. (D) T1 magnetic resonance imaging with gadolinium contrast highlighted the epidural portion of the tumour. (E) After placement of the first coil, the haemangioma was still highly vascularised. (F) The second coil successfully occluded the feeding arteries. (G) The tumour was stabilised by posterior instrumentation of T4-T8, the posterior portion of the haemangioma was resected, and the vertebral body was replaced by an expandable titanium cage and autologous bone-graft. The amount of bleeding was $2,060 \mathrm{~mL}$, and $550 \mathrm{~mL}$ red blood cell concentrate was autotransfused from the cell saver. No allogeneic blood transfusion was required. (H, I) Postoperative CT scans showed proper decompression and adequate stabilisation. The patient recovered completely from myelopathy within two months (ASIA E). ASIA, American Spinal Injury Association classification. 
and (3) allergic reactions to the embolising agents [9].

Kobayashi et al. [7] reviewed 62 patients who underwent preoperative embolisation of spinal tumours. In their cohort, the degree of embolisation itself did not have any significant effect on perioperative blood loss, but surgical invasiveness did $(p<0.001)$. Therefore, the impact of preoperative embolisation should be questioned and its benefits should be weighed against possible harms. Until now, a meta-analysis of the effect of embolisation on surgical bleeding in the published case reports and case series on AVH has not been performed. This review will summarise the weak evidence for treatment of $\mathrm{AVH}$, present a meta-analysis of bleeding related to the use of embolisation prior to surgery, and assess whether preoperative embolisation reduces blood loss during resection and/or decompression of symptomatic aggressive vertebral haemangioma.

\section{Materials and Methods}

This systematic review was registered in the PROSPERO database (CRD42014008862). On March 7th, 2014, a literature search was performed with PubMed Medline, Web of Science, and Ovid Medline using the search terms

"(aggressive OR spinal cord) AND (spinal OR vertebral) AND haemangioma”.

Limits were set to publications since 1990. The PubMed Medline search was limited to "[Title/Abstract]", and the Ovid Medline search was limited to "title".

Titles and abstracts were obtained from the respective search engines. All full-texts could be obtained from the university libraries or from openly accessible publications.

Only studies on extradural thoracic and lumbar aggressive haemangiomas were included since embolisation of cervical haemangioma is relatively contraindicated.

Case reports of AVH becoming symptomatic during pregnancy were excluded since embolisation is contraindicated in these patients due to the possible harm to the unborn. The case presented in this study was also included. The amount of bleeding $(\mathrm{mL})$ was defined as the primary outcome.

The data was treated as a between-group design with two independent groups; one treatment group (embolisation) and one control group (no embolisation). The reported means, standard deviation, and number of participants in the included studies were used to compute the means, standard deviations, and number of participants in the treatment and control groups, respectively. Sample sizes were taken into account when calculating the two groups' means by calculating the weighted means. The standard deviations of the treatment and control groups were calculated by first computing the sum of squares. In a subsequent step, the sum of squares was used to calculate the variances and the standard deviations. The means, standard deviations, and number of participants in the two groups were submitted to an independent samples $t$-test. The effect size was calculated as Cohen's $\mathrm{d}$. If not indicated otherwise, values are presented as mean \pm standard deviation.

Subgroup analysis was not performed and heterogeneity was not assessed. Due to the low quality of evidence and the fact that only case reports were available, sensitivity analysis was not performed.

Two authors assessed the risk of bias of included studies separately according to the Grading of Recommendations Assessment, Development and Evaluation (GRADE) working group guidelines for assessing risk of bias [10]. All included studies were case reports and case series; thus, both selection bias and reporting bias can be assumed. The strength of evidence was estimated and recommendations were given using the GRADE guidelines [11].

\section{Results}

The electronic search retrieved 399 publications that were screened by two co-authors. Among these, 54 publications were potentially eligible for inclusion. After fulltext review, 18 publications were included (Fig. 2). While checking for outliers, the case report by Alexander et al. [2] was excluded because the value in a single participant was more than 6 standard deviations away from the mean of the control group. All 17 included studies were case reports or case series. No comparative study was included. Twelve out of the 17 included studies were single case reports.

Among the 51 included patients, 32 were females. The mean patient age was $44 \pm 19$ years (range, 9-77 years). Also, $83 \%$ of AVH involved the thoracic spine.

Various types of interventions were used in the included studies. They varied from posterior decompression and vertebroplasty to circumferential en-bloc spondylectomy and stabilisation. Despite the fact that the different procedures are not equivalent with regard to invasiveness of the approach, selection was not performed in this context. 


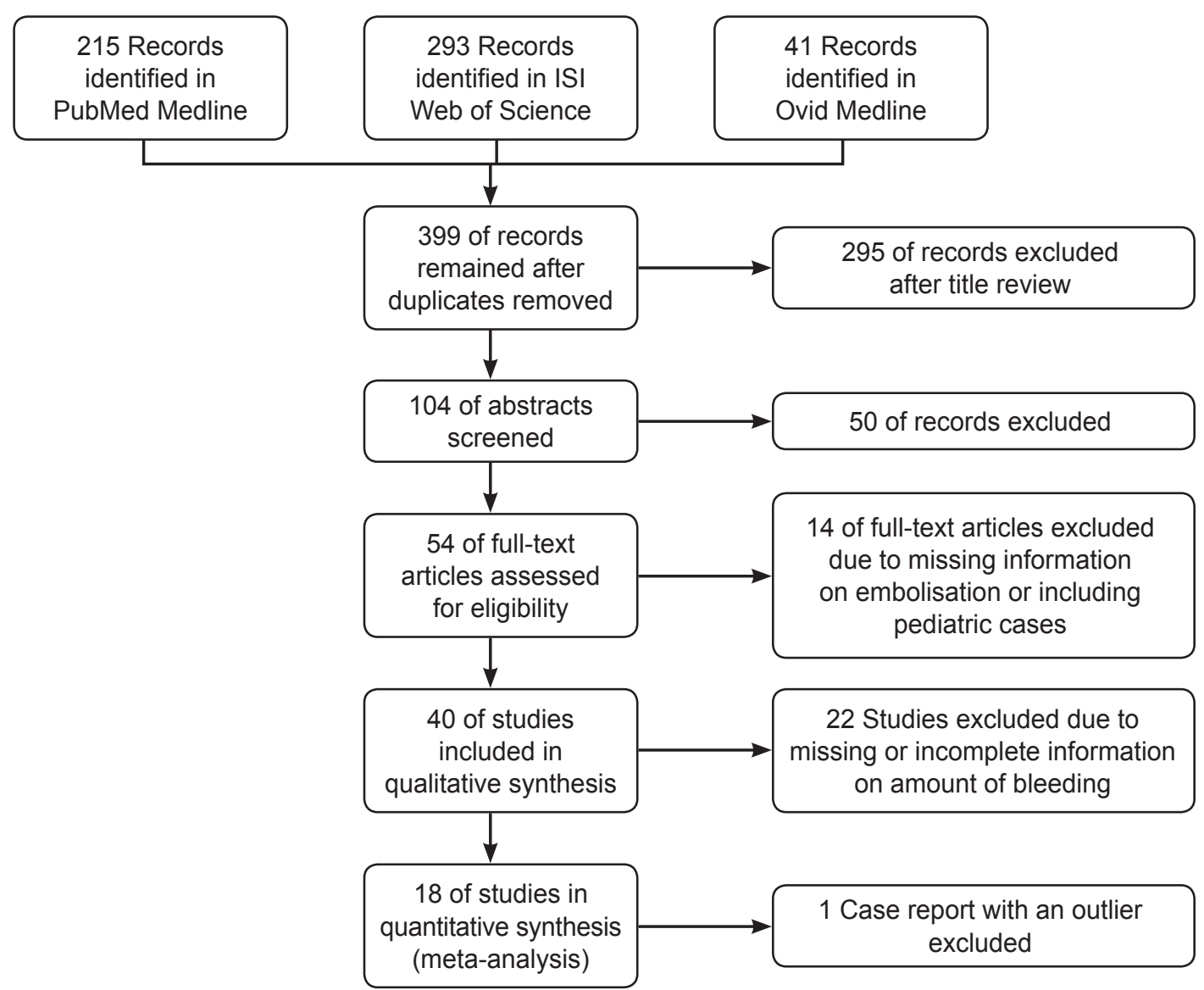

Fig. 2. Study flow diagram.

The postoperative neurological outcomes were generally positive in the published cases, irrespective of the surgical method. Only one out of the 51 cases did not show postoperative improvement (Table 1) [12-25].

The analysis indicated that there was a significant difference in the amount of blood loss between the treatment group and the control group ( $t[49]=2.59 ; p=0.013 ; 95 \%$ CI, $143-1,048 ; d=0.73)$. Patients in the embolised treatment group $(980 \pm 683 \mathrm{~mL})$ bled less than patients in the non-embolised control group $(1,629 \pm 946 \mathrm{~mL})$. The analysis suggests that embolisation causes reduction in bleeding during surgery.

\section{Discussion}

The available literature supports the use of preoperative embolisation in cases of AVH. The variability in effectiveness of embolisation is well reflected in these results. Embolisation does not seem to be the only factor contributing to reduction in bleeding; other factors such as surgi- cal technique, proper anaesthesia (i.e., using low positive end-expiratory pressure), and clotting capacity of the patients also play an important role, thus diminishing the overall effect of embolisation.

With regard to spinal surgery, the amount of surgical bleeding could be related to morbidity and mortality in the postoperative course [26]. Not only transfusion risks but also cardiovascular and pulmonary complications increase with greater blood loss [27].

Preoperative embolisation is a relatively safe procedure and reported complications are rare. Other than the transient post-embolisation syndrome with low-grade fever, pain, nausea, vomiting, and an elevated white blood cell count, serious adverse events due to accidental vascular occlusion are limited to anecdotal case reports [3].

The quality of evidence is very low. Seventeen studies were included, and all studies were either case reports or case series (Table 2). With an increase in the size of AVH, the surgeon may be more inclined to use preoperative embolisation. Blinding was not performed in the included 


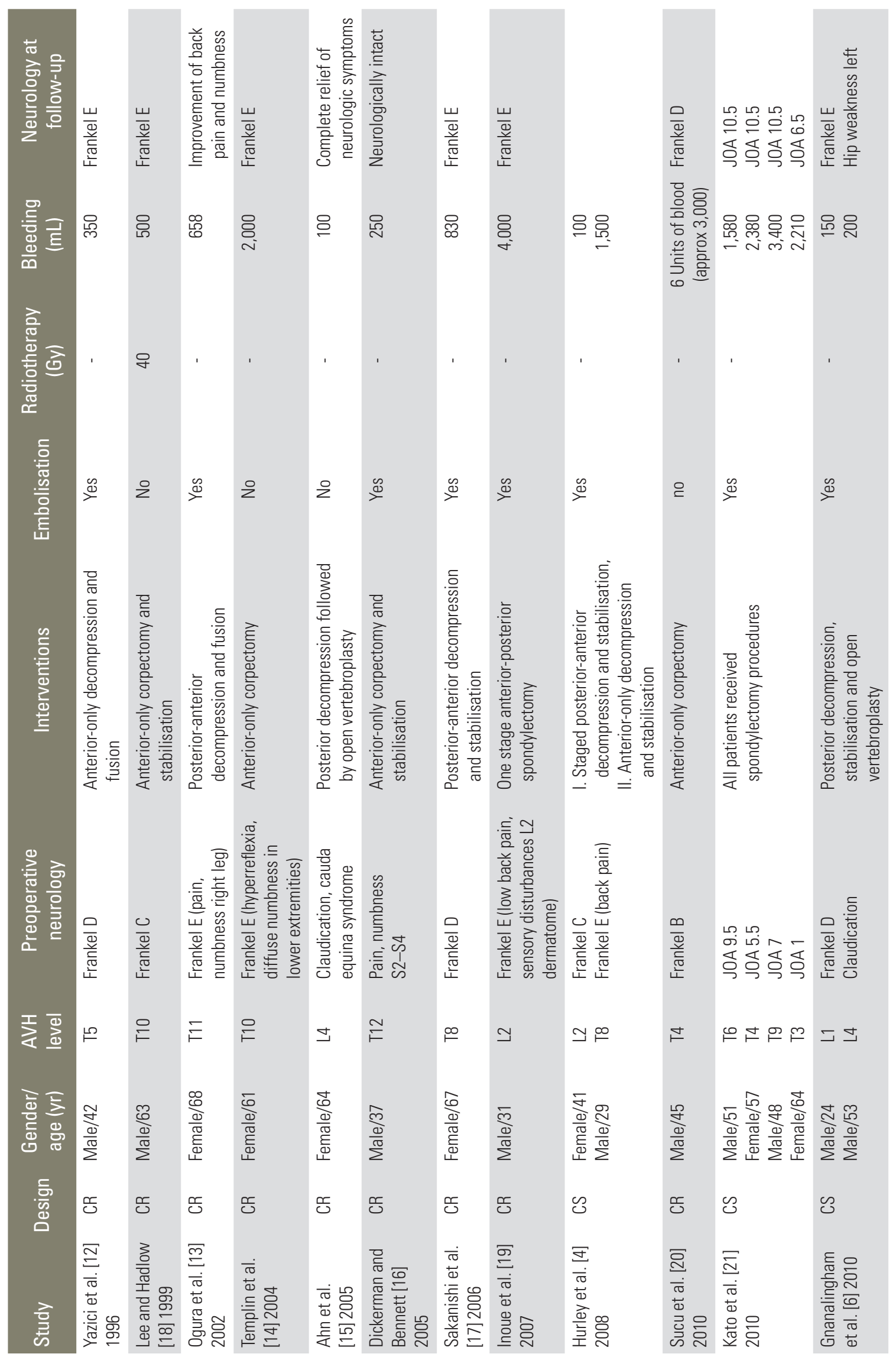




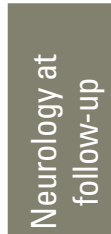

흘

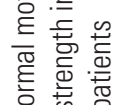

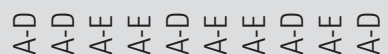

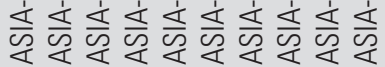
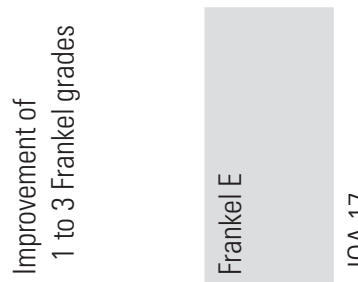

$\neq \mathscr{F}=$

吉吉吉要

产

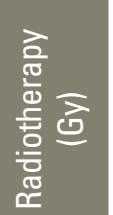

$\stackrel{\infty}{\infty}$

$\stackrel{\infty}{>}$

운
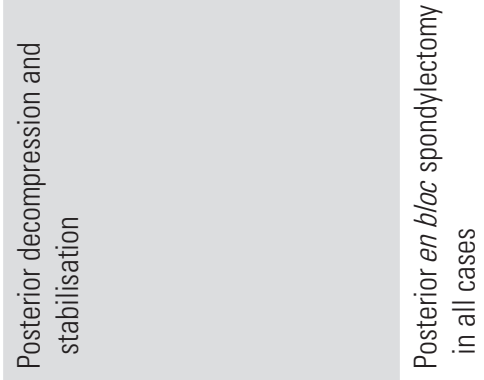

ल

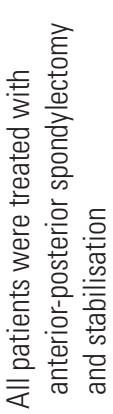

离

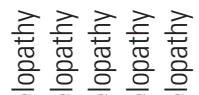

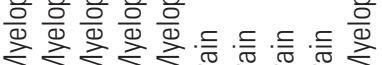

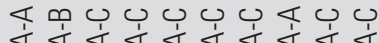

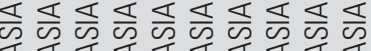

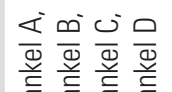

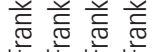

-

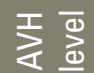

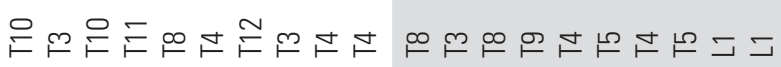

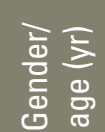

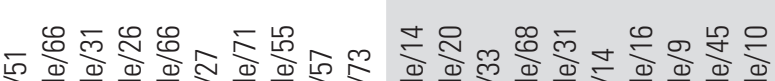

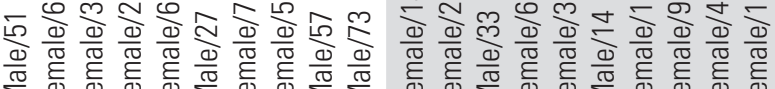

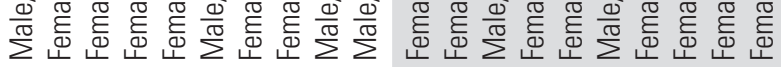

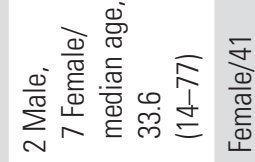

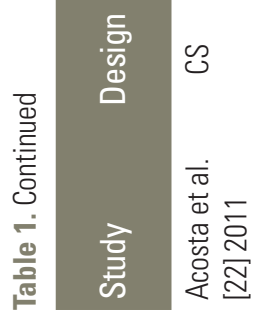

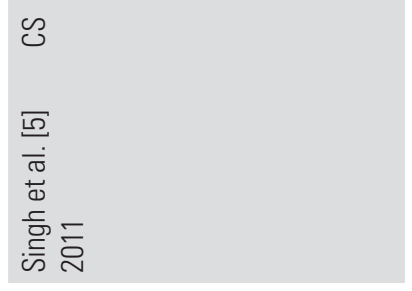

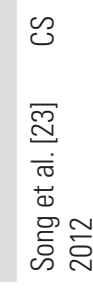

\begin{tabular}{|c|c|}
\hline 둰 & $\mathcal{O}$ \\
\hline 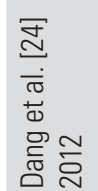 &  \\
\hline
\end{tabular}


Table 2. Bleeding with vs. without embolisation

\begin{tabular}{|c|c|c|c|c|c|c|}
\hline \multirow[b]{2}{*}{ Study } & \multicolumn{3}{|c|}{ Embolisation (mL) } & \multicolumn{3}{|c|}{ Control (mL) } \\
\hline & Mean & $\begin{array}{l}\text { Standard } \\
\text { deviation }\end{array}$ & $\mathrm{n}$ & Mean & $\begin{array}{l}\text { Standard } \\
\text { deviation }\end{array}$ & $\mathrm{n}$ \\
\hline Yazici et al. [12] 1996 & 350 & 0 & 1 & 0 & 0 & 0 \\
\hline Lee and Hadlow [18] 1999 & 0 & 0 & 0 & 500 & 0 & 1 \\
\hline Ogura et al. [13] 2002 & 658 & 0 & 1 & 0 & 0 & 0 \\
\hline Templin et al. [14] 2004 & 0 & 0 & 0 & 2,000 & 0 & 1 \\
\hline Ahn et al. [15] 2005 & 0 & 0 & 0 & 100 & 0 & 1 \\
\hline Dickerman and Bennett [16] 2005 & 250 & 0 & 1 & 0 & 0 & 0 \\
\hline Sakanishi et al. [17] 2006 & 830 & 0 & 1 & 0 & 0 & 0 \\
\hline Inoue et al. [19] 2007 & 1,000 & 0 & 1 & 0 & 0 & 0 \\
\hline Hurley et al. [4] 2008 & 800 & 990 & 2 & 0 & 0 & 0 \\
\hline Sucu et al. [20] 2010 & 0 & 0 & 0 & 3,000 & 0 & 1 \\
\hline Kato et al. [21] 2010 & 2,393 & 755 & 4 & 0 & 0 & 0 \\
\hline Gnanalingham et al. [6] 2010 & 175 & 35 & 2 & 0 & 0 & 0 \\
\hline Acosta et al. [22] 2011 & 1,370 & 769 & 10 & 0 & 0 & 0 \\
\hline Singh et al. [5] 2011 & 296 & 91 & 10 & 0 & 0 & 0 \\
\hline Song et al. [23] 2012 & 0 & 0 & 0 & 1,800 & 1,000 & 9 \\
\hline Dang et al. [24] 2012 & 0 & 0 & 0 & 1,000 & 0 & 1 \\
\hline Yao and Malek [25] 2013 & 1,250 & 733 & 4 & 0 & 0 & 0 \\
\hline Total & 980 & 683 & 37 & 1,629 & 946 & 14 \\
\hline
\end{tabular}

case reports. Not all studies reported the amount of bleeding, and 36 studies were excluded due to incomplete data.

A significant publication bias must be assumed since case reports are published only if they present a rare and unique entity. Cases with incomplete radiographic examinations, suboptimal outcome, or missing documentation are often not publishable.

Only selected databases were searched using a rather conservative search string. Studies published before 1990 were not included in the study. Therefore, there is a possibility that not all studies were identified.

\section{Conclusions}

This meta-analysis found-with reservations due to the above-mentioned limitations-a significant reduction in surgical bleeding and a large treatment effect of preoperative embolisation (Table 3 ).

The authors agreed with the strong recommendation of embolisation prior to resection surgery for symptomatic AVH [28].
It has been shown that not only embolisation, but surgical invasiveness also plays an important role in surgical bleeding in tumour surgery [7]. Due to the benign characteristics of $\mathrm{AVH}$, the least invasive procedure must be applied to treat this tumour with minimal blood loss and complications. However, biomechanical considerations may compel us to perform resection and reconstruction of anterior column elements, which are associated with greater blood loss [29].

Besides this, similar to spinal tumour surgery, selective endovascular embolisation also undeniably requires skills with a learning curve [30]. The cases with greater blood loss despite embolisation indicate that it was very likely that all feeding arteries were not occluded. To improve the success rate of embolisation, a specific training program may be helpful.

There are severe methodological limitations in the meta-analysis of the published cases since significant selection and publication biases must be assumed. The inconsistency in the results reflected by the confidence interval leaves a huge question mark over the conclusion 
Table 3. Summary of findings

\begin{tabular}{|c|c|c|c|c|c|c|}
\hline \multirow[b]{2}{*}{ Outcome } & \multicolumn{2}{|c|}{ Illustrative comparative risks } & \multirow[b]{2}{*}{$\begin{array}{l}\text { Effect } \\
\text { size } d\end{array}$} & \multirow{2}{*}{$\begin{array}{l}\text { No. of } \\
\text { participants } \\
\text { (studies) }\end{array}$} & \multirow{2}{*}{$\begin{array}{l}\text { Quality of } \\
\text { the evidence } \\
\text { (GRADE) }\end{array}$} & \multirow[b]{2}{*}{ Comments } \\
\hline & $\begin{array}{l}\text { Assumed risk } \\
\text { without } \\
\text { embolisation }\end{array}$ & $\begin{array}{l}\text { Corresponding risk } \\
\text { with embolisation }\end{array}$ & & & & \\
\hline $\begin{array}{l}\text { Surgical } \\
\text { blood } \\
\text { loss }(\mathrm{mL})\end{array}$ & $\begin{array}{l}\text { The mean surgical } \\
\text { blood loss was } \\
\text { 1,629 mL and ranged } \\
\text { across control } \\
\text { groups from } 100 \text { to } \\
3,000 \mathrm{~mL}\end{array}$ & $\begin{array}{l}\text { The mean surgical blood } \\
\text { loss with embolisation } \\
\text { was } 648 \mathrm{~mL} \text { lower }(p<0.05 \text {; } \\
95 \% \mathrm{Cl}, 143-1,048)\end{array}$ & 0.73 & $51(17)$ & $\begin{array}{c}\oplus \ominus \ominus \ominus \\
\text { very low }\end{array}$ & $\begin{array}{l}\text { Benefits of the significant } \\
\text { reduction of surgical } \\
\text { bleeding together with } \\
\text { a strong treatment } \\
\text { effect allow a strong } \\
\text { recommendation for } \\
\text { embolisation prior to } \\
\text { AVH resection. }\end{array}$ \\
\hline \multicolumn{7}{|c|}{$\begin{array}{l}\text { Embolisation for blood loss reduction in surgery for aggressive vertebral haemangioma. } \\
\text { Patient or population: adults with aggressive vertebral haemangioma. } \\
\text { Intervention: preoperative embolization. } \\
\text { Comparison: surgery without embolization. }\end{array}$} \\
\hline
\end{tabular}

GRADE Working Group grades of evidence.

- High quality: further research is very unlikely to change our confidence in the estimate of effect.

- Moderate quality: further research is likely to have an important impact on our confidence in the estimate of effect and may change the estimate.

- Low quality: further research is very likely to have an important impact on our confidence in the estimate of effect and is likely to change the estimate.

- Very low quality: we are very uncertain about the estimate.

$\mathrm{AVH}$, aggressive vertebral haemangiomas.

of this study.

Further research could improve the available evidence. Pooling of prospectively collected national registry data could increase the number of included cases. Randomised controlled trials comparing embolisation to control are not feasible due to the small number of cases.

\section{Conflict of Interest}

No potential conflict of interest relevant to this article was reported.

\section{References}

1. Jiang L, Liu XG, Yuan HS, et al. Diagnosis and treatment of vertebral hemangiomas with neurologic deficit: a report of 29 cases and literature review. Spine J 2014;14:944-54.

2. Alexander J, Meir A, Vrodos N, Yau YH. Vertebral hemangioma: an important differential in the evaluation of locally aggressive spinal lesions. Spine (Phila Pa 1976) 2010;35:E917-20.

3. Ozkan E, Gupta S. Embolization of spinal tumors: vascular anatomy, indications, and technique. Tech Vasc Interv Radiol 2011;14:129-40.

4. Hurley MC, Gross BA, Surdell D, et al. Preoperative Onyx embolization of aggressive vertebral hemangiomas. AJNR Am J Neuroradiol 2008;29:1095-7.

5. Singh P, Mishra NK, Dash HH, et al. Treatment of vertebral hemangiomas with absolute alcohol (ethanol) embolization, cord decompression, and single level instrumentation: a pilot study. Neurosurgery 2011;68:78-84.

6. Gnanalingham KK, Afridi MB, Abou-Zeid A, Herwadkar A. Minimally invasive decompression and stabilisation for extensive haemangiomas of lumbar spine. Minim Invasive Neurosurg 2010;53:275-8.

7. Kobayashi K, Ozkan E, Tam A, Ensor J, Wallace MJ, Gupta S. Preoperative embolization of spinal tumors: variables affecting intraoperative blood loss after embolization. Acta Radiol 2012;53:935-42.

8. Shi H, Jin Z, Suh DC, Lee HK, Li L. Preoperative transarterial embolization of hypervascular vertebral tumor with permanent particles. Chin Med J (Engl) 2002;115:1683-6.

9. Ishikura H, Sotozaki Y, Adachi H, Sato M, Yoshiki 
T. Granulomatous arteritis with massive eosinophilic leukocyte infiltration and transient peripheral eosinophilia subsequent to transarterial embolization therapy with a gelatin sponge. Acta Pathol Jpn 1991;41:618-22.

10. Guyatt GH, Oxman AD, Vist G, et al. GRADE guidelines: 4 . Rating the quality of evidence: study limitations (risk of bias). J Clin Epidemiol 2011;64:407-15.

11. Brozek JL, Akl EA, Compalati E, et al. Grading quality of evidence and strength of recommendations in clinical practice guidelines part 3 of 3 . The GRADE approach to developing recommendations. Allergy 2011;66:588-95.

12. Yazici M, Iyigun OL, Gulman B, Rakunt C, Cizmeli O. Vertebral hemangioma presenting with intermittent claudication. Eur Spine J 1996;5:131-3.

13. Ogura T, Mori M, Hayashida T, Osawa T, Hase H. Spinal reconstruction for symptomatic thoracic haemangioma using a titanium cage. Postgrad Med J 2002;78:559-61.

14. Templin CR, Stambough JB, Stambough JL. Acute spinal cord compression caused by vertebral hemangioma. Spine J 2004;4:595-600.

15. Ahn H, Jhaveri S, Yee A, Finkelstein J. Lumbar vertebral hemangioma causing cauda equina syndrome: a case report. Spine (Phila Pa 1976) 2005;30:E662-4.

16. Dickerman RD, Bennett MT. Acute spinal cord compression caused by vertebral hemangioma. Spine J 2005;5:582-4.

17. Sakanishi H, Hoshi K, Nakajima S, et al. Vertebral hemangioma compressing the thoracic spinal cord: application of computer-aided navigation and intraoperative spinal sonography for surgery through anterior and posterior approaches. J Orthop Sci 2006;11:294-7.

18. Lee S, Hadlow AT. Extraosseous extension of vertebral hemangioma, a rare cause of spinal cord compression. Spine (Phila Pa 1976) 1999;24:2111-4.

19. Inoue T, Miyamoto K, Kodama H, Hosoe H, Shimizu $\mathrm{K}$. Total spondylectomy of a symptomatic hemangioma of the lumbar spine. J Clin Neurosci 2007;14:8069.

20. Sucu HK, Gelal F, Erol A, Tunakan M. Late surgical treatment of an aggressive vertebral hemangioma: case report. J Neurol Sci Turk 2010;27:88-92.
21. Kato S, Kawahara N, Murakami H, et al. Surgical management of aggressive vertebral hemangiomas causing spinal cord compression: long-term clinical follow-up of five cases. J Orthop Sci 2010;15:350-6.

22. Acosta FL Jr, Sanai N, Cloyd J, Deviren V, Chou D, Ames CP. Treatment of Enneking stage 3 aggressive vertebral hemangiomas with intralesional spondylectomy: report of 10 cases and review of the literature. J Spinal Disord Tech 2011;24:268-75.

23. Song RX, Zhang YG, Zhang XS, Zheng GQ, Wang Y. One-stage total en bloc spondylectomy and reconstruction via a single posterior approach for thoracic vertebral symptomatic hemangioma associated with spinal cord dysfunction. Zhonghua Wai Ke Za Zhi 2012;50:342-5.

24. Dang L, Liu C, Yang SM, et al. Aggressive vertebral hemangioma of the thoracic spine without typical radiological appearance. Eur Spine J 2012;21:1994-9.

25. Yao KC, Malek AM. Transpedicular N-butyl cyanoacrylate-mediated percutaneous embolization of symptomatic vertebral hemangiomas. J Neurosurg Spine 2013;18:450-5.

26. Shaffrey E, Smith JS, Lenke LG, et al. Defining rates and causes of mortality associated with spine surgery: comparison of 2 data collection approaches through the Scoliosis Research Society. Spine (Phila Pa 1976) 2014;39:579-86.

27. Woods BI, Rosario BL, Chen A, et al. The association between perioperative allogeneic transfusion volume and postoperative infection in patients following lumbar spine surgery. J Bone Joint Surg Am 2013;95:2105-10.

28. Andrews JC, Schunemann HJ, Oxman AD, et al. GRADE guidelines: 15. Going from evidence to recommendation-determinants of a recommendation's direction and strength. J Clin Epidemiol 2013;66:72635.

29. Berkefeld J, Scale D, Kirchner J, Heinrich T, Kollath J. Hypervascular spinal tumors: influence of the embolization technique on perioperative hemorrhage. AJNR Am J Neuroradiol 1999;20:757-63.

30. Jabbour P, Chalouhi N, Tjoumakaris S, et al. The Pipeline Embolization Device: learning curve and predictors of complications and aneurysm obliteration. Neurosurgery 2013;73:113-20. 